\title{
O booktrailer como estratégia de divulgação: o caso da obra de Hilda Hilst
}

DOI: http://dx.doi.org/10.21165/el.v50i3.3062

\author{
Matheus Nogueira Schwartzmann' \\ Gustavo Henrique Rodrigues de Castro²
}

\section{Resumo}

Partindo do ponto de vista dos níveis de pertinência da análise semiótica (J. Fontanille), em diálogo com a noção de paratexto (G. Genette), esse artigo analisa como a prática de pré-venda de livro pode determinar a circulação de uma obra. Para isso, examinamos o booktrailer homônimo da obra Da poesia, da escritora brasileira Hilda Hilst [1930-2004], publicado no canal de Cia. das Letras no YouTube. Ao tomar o booktrailer como uma estratégia, e após discorrer sobre as especificidades do seu suporte formal, concluímos que a prática de pré-venda engloba a plataforma YT Ihe conferindo uma função modal no interior da cena predicativa: firmar um contrato de compra e de leitura com o destinatário, por meio da oferta de valores literários e comerciais. Sob esse ponto de vista, o problema do "valor" (obra popular, canônica etc.) encontra sua pertinência para além do texto literário, nas interfaces que ele estabelece com outros sistemas socioculturais (o universo editorial, o universo acadêmico etc.) que determinam as modalidades de circulação e o estatuto da obra junto à cultura.

Palavras-chave: Hilst; Hilda; paratexto; práticas semióticas; semiótica francesa.

1 Universidade Estadual Paulista "Júlio de Mesquita Filho", Assis, São Paulo, Brasil; matheus.schwartzmann@gmail.com; http://orcid.org/0000-0002-2887-3570

2 Universidade Estadual Paulista "Júlio de Mesquita Filho", Araraquara, São Paulo, Brasil; g.castro@unesp.br; http://orcid.org/0000-0003-4486-9579 


\title{
The book trailer as a semiotic practice: strategies for disseminating Hilda Hilst's work
}

\begin{abstract}
Starting from the point of view of the levels of the relevance of semiotic analysis ( $\mathrm{J}$. Fontanille), in dialogue with the concept of paratext (G. Genette), this paper analyzes how the book pre-sale practice can determine the circulation of a work. To do so, the homonymous book trailer of the work Da poesia by Brazilian author Hilda Hilst [19302004], published on Cia. das Letras's YouTube channel was examined. By considering the book trailer as a strategy and after discussing the specifics of its formal support, the conclusion was that the practice of pre-sale encompasses the YT platform. Such practice gives it a modal function: signing a purchase and reading contract with the addressee, by offering them literary and commercial values. Therefore, the matter of "value" (canonical, popular work, etc.) finds its relevance beyond the literary text in the interfaces established with other sociocultural systems such as the market. They determine the modalities of circulation and the status of the work within the culture.
\end{abstract}

Keywords: Hilst, Hilda; Paratext; Semiotic practices; French Semiotics.

\section{Considerações iniciais}

Hilda Hilst [1930-2004] foi uma autora bem avaliada pela crítica especializada desde sua aparição no cenário literário brasileiro nos anos de 1950. No entanto, as grandes editoras nacionais demoraram algum tempo para se interessar por sua literatura. Hilst foi publicada por editoras pouco conhecidas por quase quarenta anos, de modo que a gestão de sua obra - impressa em pequenas tiragens e com distribuição limitada (DINIZ, 2013), dificultou o acesso aos seus livros. Esse modelo de publicação acabou por consolidar Hilst como a escritora de uma obra premiada e aclamada pela crítica, mas que permaneceu "ignorada" pelas "grandes editoras" e pelo leitor não especializado até muito recentemente.

O mesmo não pode ser dito do seu estilo de vida, que sempre recebeu atenção de um público específico, interessado pela vida privada de escritores e artistas da alta sociedade brasileira. Suas "conversas com mortos", seu "estilo de vida ermitão" e sua "liberdade sexual" Ihe conferiram certa popularidade e presença na mídia da época, que sua obra só alcançaria anos mais tarde, precisamente a partir da década de 2000. Foi quando Hilst passou a ser publicada por editoras nacionais de grande envergadura: de 2001 a 2016 por Globo Livros e a partir de 2017, por Companhia das Letras. Nesse mesmo período, a obra de Hilst foi traduzida para quatro idiomas (inglês, francês, espanhol e catalão), tendo inclusive sido homenageada pela "Feira Literária de Paraty-Flip" na edição de 2018, além de ter emplacado algumas listas de mais vendidos no mesmo ano. 
O problema da (má) circulação da obra de Hilst, que atualmente parece estar se resolvendo, já foi tema de alguns estudos, como o de Ana Cláudia Felix Gualberto (2015) e o de Fernanda Shcolnik (2014). Partindo de categorias como cânone, autoria e gênero, Gualberto (2015, p. 82) conclui que "a prosa auto-consciente [sic]" de Hilst fez "com que seu texto diferisse do exigido pelo mercado editorial em sua época". Já para Shcolnik (2014, p. 466), teria sido o "trânsito ambíguo [...] entre as esferas da consagração e da maldição, em que pareceu situar-se predominantemente na segunda" o que levou Hilst à "rejeição" das editoras e dos leitores.

Já segundo Vilma Arêas e Berta Waldman (1989), em artigo muito anterior a esses trabalhos, Hilst teria ficado conhecida como "a senhora que apareceu no Fantástico [...] dizendo que gravava vozes de mortos". Uma "Hilda provocadora, desbocada, obscena, meio louca, eremita, arredia, indomesticável [...]". Para as autoras, "Essa imagem [...] acabou por dificultar o acesso à obra, revestindo-a com um misto de impenetrabilidade e fama (ARÊAS; WALDMAN apUd HILST, 2017a, p. 533).

Em certa medida, esses estudos compartilham esta mesma hipótese: teria sido a "personalidade" de Hilda Hilst, o seu estilo "pessoal" e/ou literário "polêmico", o que teria levado sua obra a esse quadro de invisibilidade. Uma hipótese semelhante foi retomada em Da poesia (HILST, 2017), obra de poemas completos publicada por Companhia das Letras, cujo booktrailer homônimo analisaremos aqui. Segundo o "Posfácio" desse volume, "o descompasso entre ser vista e ser lida foi uma constante no trabalho de Hilst. A publicação desta Da poesia se inscreve no rol de iniciativas que buscam acertar esse compasso" (HERINGER apud HILST, 2017, p. 532).

Em estudo anterior (CASTRO, 2021), buscamos demonstrar que essa estratégia de "acertar o compasso entre ser vista e ser lida" não ocorre, exatamente, como é anunciada em Da poesia (HILST, 2017). Se ela consiste em corrigir um quadro de invisibilidade da obra, construído em função da personalidade "polêmica" de "Hilda", a estratégia editorial de Companhia das Letras deveria se afastar dos discursos que levaram a "vida privada" de Hilda Hilst a ter mais popularidade que sua obra. No entanto, em Da poesia (HILST, 2017) nos parece ocorrer o contrário: a construção do ator Hilda Hilst está fortemente ancorada no universo discursivo no qual se assenta essa identidade "polêmica" que, segundo a crítica, teria levado justamente ao desinteresse pela obra.

A maioria dos estudos que conhecemos, como os que citamos linhas antes, discute o problema da circulação da obra de Hilst tendo em vista os mecanismos de triagem, responsáveis pela seletividade do "campo literário". Dito de outro modo, são discutidos os fatores que levaram sua obra à exclusão do grande cenário literário nacional. Nesse sentido, como a consagração de Hilst é ainda um fato recente, a crítica pouco pôde tratar dos discursos e práticas que contribuíram com a construção desse novo quadro, marcado pela visibilidade e pela popularidade da obra. 
Ao nosso ver, esse novo cenário teria mecanismos de mistura $^{3}$ em suas bases, responsáveis pela acomodação da obra de Hilst no centro do "campo literário". Dentre esses mecanismos, podemos elencar o estabelecimento da rede paratextual da obra. Segundo Gérard Genette (2009), os paratextos são textos (prefácios, notas de edição, textos críticos) localizados dentro (peritextos) ou fora da obra (epitextos) visando comentá-la, avaliá-la etc. Eles podem atuar na construção de uma grade de leitura e/ou de circulação, na medida em que são fundamentais para a divulgação da obra. É este último caso que nos interessa aqui.

A partir de Genette (2009), propomos pensar em paratextos de diferentes estatutos. Os paratextos "oficiais", que são atribuídos a instâncias enunciativas correlatas à instância de edição da obra, e os paratextos oficiosos, atribuídos a outras instâncias enunciativas ${ }^{4}$. No que concerne às estratégias atuais de divulgação da obra, temos o que se pode chamar de paratextos oficiais de divulgação. Essa distinção ainda provisória é o que nos permite tratar aqui do Booktrailer: Da poesia (CIA. DAS LETRAS, 2017) como um paratexto oficial (de divulgação), publicado no canal do YouTube dessa editora, quando da pré-venda de Da poesia (HILST, 2017).

Acreditamos que paratextos como esse são capazes de determinar a circulação de uma obra, nesse caso, a obra de Hilst, uma vez que recorrem a práticas e suportes de maior ou menor visibilidade. Portanto, nesse cenário podemos (i) examinar as estratégias de venda contidas em Booktrailer: Da poesia (CIA. DAS LETRAS, 2017); (ii) observar a estratégia editorial adotada e (iii) elucidar como a prática de pré-venda pode determinar a circulação (no sentido da popularização) dessa obra. Para tanto, o percurso teórico-metodológico adotado aqui é o da Semiótica de inspiração greimasiana, especialmente os trabalhos de Jacques Fontanille (Cf. 2008a, 2008b) sobre as práticas semióticas, em diálogo com propostas de Gérard Genette (Cf. 2009) a respeito dos paratextos editoriais.

\section{A prática de pré-venda e a cena predicativa}

Segundo Fontanille (apud PORTELA, 2006, p. 181), "as práticas constituem-se em sua superfície por um conjunto de atos". Isto é, o aspecto mais evidente de uma prática é o seu caráter processual e hierárquico, que encadeia diversas ações. Se reduzidas essas ações podem ser tomadas como predicados (FONTANILLE, 2008b). Nesse sentido, poderíamos

3 Segundo esse ponto de vista, na triagem ocorreria a restrição da circulação entre/dos os objetos. Já na mistura, a circulação seria maior e, portanto, mais rápida (ZILBERBERG; FONTANILLE, 2001, p. 27). Mecanismos como esses podem explicar a "sensação" de pertencimento ou de exclusão de um autor quanto ao grupo de escritores canônicos, por exemplo.

4 Nesse sentido, por exemplo, um paratexto de divulgação de Da poesia (HILST, 2017), veiculado no blog de Companhia Das Letras, seria um paratexto oficial. Já uma postagem em um blog qualquer de literatura seria um paratexto oficioso, ainda que retome e cite um paratexto oficial. 
dizer que a prática de circulação da obra literária é construída por um encadeamento de diversas ações-predicado, ao longo das quais a experiência da prática é manifestada (SCHWARTZMANN, 2009) por cenas predicativas, como editar, pré-vender, publicar, vender, avaliar etc.:

\begin{abstract}
[...] uma prática pode comportar um ou vários processos (um ou vários predicados), atos de enunciação que implicam papéis actanciais desempenhados, entre outros, pelos próprios textos ou imagens, por seus objetos-suportes, por elementos do ambiente, pelo transeunte, pelo usuário ou pelo observador, tudo o que forma a "cena" típica de uma prática. (FONTANILLE, 2008a, p. 21).
\end{abstract}

Isolados, os "atos predicativos" não dizem muito sobre o modo como estão implicados na produção do discurso sobre a obra, nem sobre o seu papel ou função. No entanto, se levarmos em conta o momento da publicação de Da poesia (2017) e do seu Booktrailer (2017), é possível identificar uma hierarquia presidindo as relações que cada açãopredicado pode estabelecer no interior da cena-prática da pré-venda. Isto é, podemos assumir que se trata de uma estratégia organizada em torno de um projeto enunciativo global, com etapas hierarquizadas: publicação do booktrailer na internet (27 mar. 2017) e lançamento da publicação de Da poesia (24 abr. 2017). Nesse sentido, o aspecto apriorístico do booktrailer corrobora justamente sua dimensão estratégica: a "aclimatação" da obra a universos discursivos específicos delimitados no interior da cultura, que organizam sistemas de valores (SCHWARTZMANN, 2021) que participam da construção de um gosto e de um público para a obra.

Embora possamos assumir previamente que o papel de um booktrailer seja o de divulgação, a sua especificidade de "alerta de pré-venda" só se evidencia se o inserirmos nesse conjunto de atos hierarquizados. Isso porque existem outros paratextos de divulgação que não se realizam segundo essa estratégia de pré-venda que discutimos, como as resenhas (acadêmicas ou jornalísticas) sobre a obra. É nesse sentido que Fontanille afirma: uma prática semiótica "se constitui por um conjunto de atos cuja significação raramente é conhecida de antemão", pois é preciso hierarquizá-los para que se entenda o seu papel (FONTANILLE apud PORTELA, 2006, p. 181, grifos nossos). Em outras palavras, o sentido desses atos - e, por extensão, o da própria prática - constrói-se "em tempo real", por "adaptações" recíprocas (FONTANILLE apud PORTELA, 2006, p. 181).

Uma prática também "se define [...] por sua temática principal, que fornece o seu "predicado central". Em torno desse predicado se organiza um "dispositivo actancial" que compreende "um operador, um objetivo" e um objeto (FONTANILLE apud PORTELA, 2006, p. 181). Neste caso, o tema principal da prática de pré-venda é "pré-venda" e o seu predicado, "pré-vender", o que equivale a criar um nicho de consumidores (leitores) previamente engajados na leitura da obra. Pensando nessas funções indicadas por Fontanille, é possível narrativizar esse predicado do seguinte modo: "Companhia das 
Letras (operador) divulga (objetivo) o lançamento de Da poesia (objeto 1) com booktrailer homônimo (objeto 2)".

Como já indicamos anteriormente, o modo de reunir todas essas noções (atos, práticas, operadores, objetos) é organizando-as em uma cena predicativa, que comporta duas noções fundamentais: delimitação e hierarquização. Nesse aspecto, do ponto de vista editorial, podemos considerar que a circulação da obra literária na cultura ocorre segundo um percurso relativamente canônico, dotado de quatro estágios hierarquizados: a pré-venda (anúncios, divulgação etc.), a publicação (primeira edição), a republicação (reedições, novas edições, outras edições etc.) e o comentário (resenhas, artigos, matérias etc. $)^{5}$. Trataremos aqui do primeiro estágio: a pré-venda.

\section{O canal "Companhia das Letras": estratégias de divulgação e de contrato}

O YouTube é considerado um site de cultura participativa (BURGESS; GREEN, 2009, p. 14) que estabelece uma série de diretrizes ${ }^{6}$ sobre os conteúdos que podem ou não ser publicados (SCHWARTZMANN, 2013, p. 76-77). No YouTube, as práticas de edição que gerenciam esses conteúdos permitem que os usuários da rede indiquem a validade, a qualidade e o interesse com relação a cada vídeo postado, por meio de ferramentas disponíveis em cada uma das páginas.

Conforme aponta Schwartzmann (2013, p. 77-78), ferramentas como "responder" delimitam "os contornos do interesse ${ }^{7}$ de um comentário veiculado, na medida em que se abrem campos para que sejam tecidos comentários aos comentários". Portanto, a ferramenta "permite [...] muita autonomia ao usuário, que pode transformar o espaço de comentários do YouTube em uma arena particular de debates" (2013, p. 78). Essa arena

5 As quatro práticas elencadas são práticas mais englobantes e, por isso, mais salientes e com maior potencial taxionômico. Como se pode imaginar, a pré-venda engloba práticas como a de marketing. As práticas de publicação e de republicação englobam práticas como as de edição e de crítica literária etc.

6 As diretrizes podem ser consultadas em http://www.youtube.com/t/community_guidelines. O título da seção é: "Dicas de Diretrizes para Comunidades". Ela se divide em seis partes que restringem, organizam e delimitam, até mesmo legalmente, as formas de uso da rede: Sexo e Nudez; Apologia ao ódio; Chocante e Repugnante; Atos perigosos e ilegais; Crianças; Direitos Autorais.

7 É possível ainda citar, nos comentários, outros usuários que estejam cadastrados na rede do YouTube, disseminando e multiplicando a visibilidade do vídeo. É também possível copiar o link do vídeo, migrando seu conteúdo para redes sociais e sistemas de troca de mensagens simultâneas. Esses procedimentos de disseminação acabam por ratificar, estrategicamente, o interesse do conteúdo do vídeo compartilhado/comentado. 
surge como simulacro de uma comunicação direta entre donos de canal e usuários da rede, e se expande, nesta reflexão, para uma relação direta entre a casa editorial e os seus leitores habituais, que seguem os conteúdos de Companhia das Letras nas suas distintas plataformas, acompanhando (idealmente) o que há de novo na editora:

Figura 1. Canal da Cia. das Letras no YT

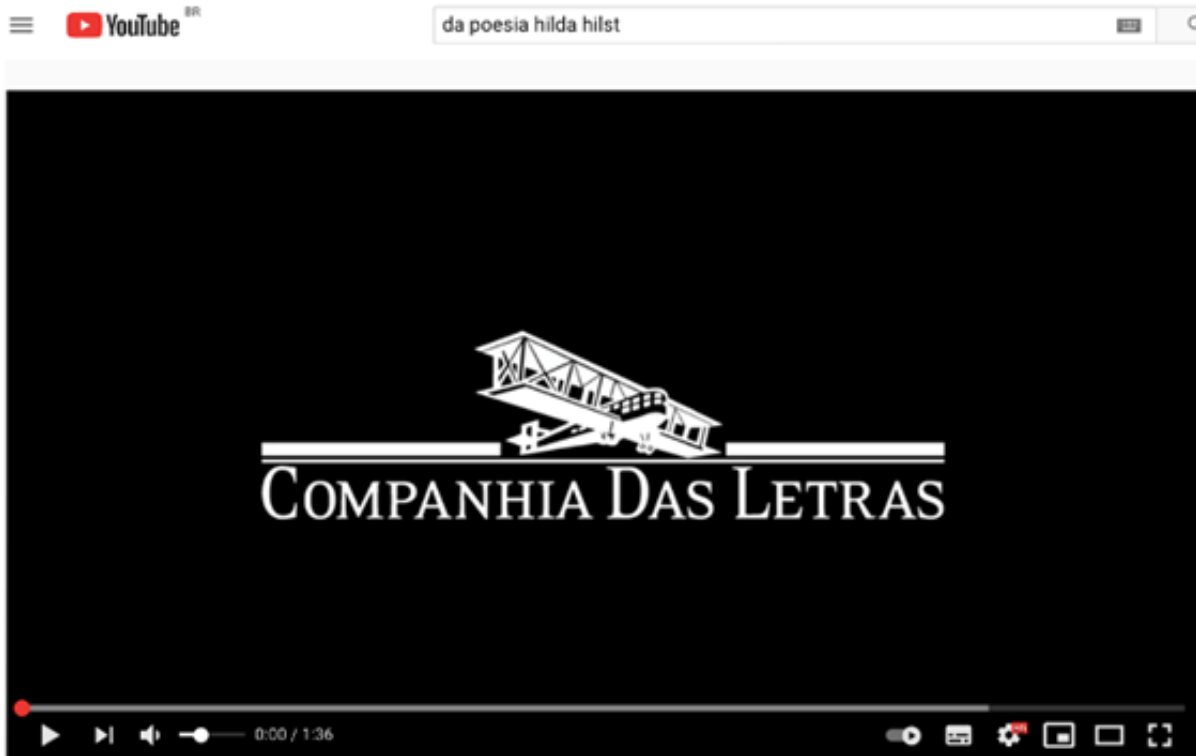

Booktrailer: "Da poesia", de Hilda Hilst

7.028 visualizaçбes - 27 de mar, đe 2017

It 272 910 $\rightarrow$ COMPARTILHAR $\equiv+$ SALVAR $\ldots$

Companhia das Letras 0

INSCREVER-SE

77,5 mil inscritos

Com imagens da Casa do Sol, ouça Hilda Hilst lendo "Da noite".

Pela primeira vez, toda a lavra poética da autora de "Bufólicas" está reunida em um só livro, que inclui, além de mais de 20 títulos, uma seção de inéditos e fortuna crítica. 0 material contém posfácio de Victor Heringer, carta de Caio Fernando Abreu para Hilda, dois trechos de Lygia Fagundes Telles sobre a amiga e uma entrevista cedida a Vilma Áreas, publicada no "Jornal do Brasil" em 1989.

A poesia de Hilda - que ganha forma em cantigas, baladas, sonetos e poemas de verso livre explora a morte, a solidão, o amor erótico, a loucura e o misticismo. Ao fundir o sagrado e o profano, a poeta se firmou como uma das vozes mais transgressoras da literatura brasileira do século XX.

"Da poesia" chega às livrarias no dia 24 de abril. Garanta o seu:

Amazon: http://amzn.to/2n1u0wA

Cultura: http://bit.ly/2nfrl $4 \mathrm{v}$

Saraiva: http://bit.ly/2nLcEnD

Direção e edição: Maria Lutterbach

Câmera: Haroldo Saboia

Trilha: Collecting samples (Blue Dot Sessions)

Fonte: https://youtube.com/watch?v=3P6f2HeXEtM\&t 
Conforme apontado por Schwartzmann (2013), as propriedades formais do suporte hierarquizam instâncias enunciativas interdependentes, que colocam em jogo diferentes valores. Na instância do vídeo, os protocolos de interação (curtir, não-curtir etc.) indicam que o valor em jogo nesse contrato é a avaliação positiva ou negativa do vídeo pelo destinatário ${ }^{8}$. Na instância seguinte, o editorial, encontramos o logotipo de Companhia das Letras, o número de inscritos e o botão "INSCREVER-SE". O valor em jogo nesse contrato é a manutenção, já que ele visa fidelizar o destinatário ao canal. Esse contrato pode estar virtualizado, no caso do usuário não inscrito ("INSCREVER-SE"), ou realizado no caso de um seguidor ("INSCRITO").

Depois, temos a instância enunciativa que dá lugar à descrição do vídeo. Nessa região, o suporte formal coage o enunciador do canal a um programa de uso, pois como o próprio YouTube sugere, trata-se de um espaço destinado à descrição do vídeo. Os valores aí em jogo são os de informação e/ou detalhamento.

A última instância enunciativa é a dos comentários. Os sujeitos implicados nessa instância, "ainda que [...] submetidos a determinadas regras, têm [alguma] autonomia", pois podem "migrar seus comentários para outras redes, recomendar publicações, denunciá-las etc.". Essa autonomia revela "valores individuais bem mais marcados, que dão maior responsabilidade para os sujeitos comentadores" e indicam, portanto, o valor em jogo nessa última instância: a conduta (SCHWARZMANN, 2013, p. 76).

Se nos voltarmos novamente para cada uma dessa instâncias, veremos que o destinador permanece correlato ao enunciador "Companhia das Letras". Já o destinatário pressuposto por cada instância é redefinido sucessivamente, de acordo com os valores modais e descritivos em jogo no contrato. Vejamos como isso ocorre.

Ao lançar mão de uma plataforma on-line que impõe protocolos de interação como "curtir" e "não curtir" (Cf. instância do vídeo), a prática de pré-venda controlada por Companhia das Letras autoriza o comprador em potencial (o seu leitor ideal) a avaliar o booktrailer. Assim, em um nível mais superficial, o destinatário pode assumir o papel de destinador, já que é capaz de sancionar o vídeo, sem entrar em disjunção com seu próprio papel (de destinatário) em um nível mais profundo. Trata-se, portanto, da atribuição de um poderfazer, da doação de uma competência judicativa.

$\mathrm{Na}$ instância seguinte, a do editorial, o destinatário pode passar de um contrato virtualizado (inscrever-se) para um contrato realizado (inscrito). A realização do contrato implica a sobremodalização do papel temático (GREIMAS; COURTÉS, 2016, p. 357) do

8 Nesse sentido, ações como "compartilhar", "baixar" e "salvar" têm a mesma função judicativa. 0 sujeito que compartilha, salva ou baixa um vídeo o faz porque o avaliou positiva ou negativamente. 
leitor, que deixaria de ser um "usuário do YouTube" para se tornar um seguidor do canal de Companhia das Letras. Trata-se, portanto, da atribuição de um poder-ser, isto é, de uma competência existencial e identitária.

Já na instância de descrição do vídeo, o destinatário tem acesso a detalhes da postagem, o que lhe confere um caráter informacional. Nesse sentido, o valor que está em jogo é uma competência cognitiva, um poder-saber sobre o vídeo veiculado. Por fım, na instância do comentário, a interação entre os sujeitos é regulada pelo valor da conduta. São os comentários que permitem conhecer as escolhas feitas pelos sujeitos quando de sua relação com objeto da postagem e com os outros sujeitos. Trata-se, assim, da atribuição de uma competência ética, que confere aos sujeitos um querer-fazer:

Quadro 1. Valores em jogo nas instâncias enunciativas da página.

\begin{tabular}{|c|c|c|}
\hline instâncias enunciativas & valores modais & valores descritivos \\
\hline vídeo & poder-fazer & avaliação \\
\hline editorial & poder-ser & manutenção \\
\hline descrição & poder-saber & Informação/detalhamento \\
\hline comentário & querer-fazer & conduta \\
\hline
\end{tabular}

Fonte: elaboração nossa a partir de: https://youtube.com/watch?v=3P6f2HeXEtM\&t.

Até aqui, identificamos instâncias enunciativas independentes, nos atendo apenas às propriedades do suporte formal (englobamentos, hierarquizações do tipo superior/ inferior...). Vimos que cada região da página on-line pode ser entendida como uma instância relativamente autônoma que determina as relações possíveis entre o usuário do canal, o canal, o objeto da postagem (o booktrailer) e o objeto da pré-venda (a obra de Hilst).

No entanto, o exame do suporte formal revela apenas formas de hierarquização muito elementares. Isto é, podemos supor os diferentes papéis que sujeitos e objetos implicados na pré-venda podem ou não assumir, segundo uma relação possível, firmada por determinado valor (poder-ser, poder-fazer, poder-saber, querer-fazer). Para responder como os sujeitos são levados a estabelecer esses papéis e relações, e como se destinam os valores, é preciso passar para o nível do texto-enunciado. Antes, no entanto, vamos refletir um pouco sobre a necessidade e o alcance dessa mudança de nível.

Como tudo o que o canal oferece ao enunciador são possibilidades (de inscrição, divulgação, engajamento, interação etc.), enquanto suporte-formal a página do YT funciona como uma espécie de eixo de seleção. É a partir das possibilidades de uso oferecidas pela plataforma - e portanto selecionáveis pelo enunciador do canal - que 
o texto será construído, via extração de propriedades formais pertinentes para a sua enunciação. Trata-se da mesma relação que Schwartzmann (2009) afirma ocorrer entre suporte formal e suporte material. Segundo ele:

O suporte formal apresenta-se como as estruturas que recebem as inscrições, ou seja, o conjunto de regras [...] decalcadas da sua materialidade. Ambos os suportes estão implicados entre si, já que o suporte formal resulta da extração de propriedades presentes no suporte material, que, por sua vez, Ihe impõe limites, ou "tendências substanciais", que devem ser selecionadas, apuradas e sistematizadas. (SCHWARTZMANN, 2009, p. 118).

Adotando essa mesma lógica, podemos pensar se o texto não resultaria também da extração de propriedades, nesse caso, presentes no suporte formal. Dito de outro modo, antes de se submeter às "coerções discursivas", a textualização seria convocada a responder às tendências formais do suporte, no âmbito do objeto de inscrição que seleciona.

No Dicionário, Greimas afirma que a linearidade do significante é a principal coerção imposta à textualização (GREIMAS; COURTÉS, 2016). Na sua hipótese, a questão do significante procurado pelo discurso determina o modo de linearidade imposto ao texto, que poderá ser temporal, espacial ou espaço-temporal, segundo o tipo de texto a ser produzido (verbal, visual ou sincrético). Entretanto, como ele afırma, a linearidade é "compensada" pela elasticidade do discurso de forma que a "natureza do significante que ele [o texto] terá de encontrar no momento da manifestação" acaba sendo neutralizada (GREIMAS; COURTÉS, 2016, p. 504). Assim, independentemente da natureza do significante e, consequentemente, do tipo de texto/discurso que se quer produzir, a linearidade se impõe como princípio, condição à toda textualização.

Por outro lado, quando se trata das coerções formais, a natureza do suporte procurado pelo gesto enunciativo (de inscrição) não pode ser neutralizada. Pensemos em um caderno em branco e em um poema a ser escrito. Podemos escrevê-lo na capa do caderno, em uma de suas páginas ou com uma letra muito grande, de modo que ele ocupe todas as folhas. Com esse exemplo simples podemos notar que a "extensidade" do suporte (as páginas em branco) se oferece ao gesto enunciativo (de inscrição) como uma tendência formal, não como uma coerção à qual o texto do poema deveria se submeter.

Portanto, no primeiro caso, a linearidade é uma condição de todo discurso, uma coerção, de maneira que a convocação de um significante (verbal, visual ou sincrético) não nos diz muito sobre a instância enunciativa que produziu o texto. No segundo caso, o das propriedades formais, os protocolos de inscrição do suporte são uma tendência, 0 que significa que podem ser assumidos segundo diversas modalidades de inscrição: totalidade/parcialidade, acordo/desacordo, equilíbrio/desequilíbrio etc. 
Uma vez decalcadas do suporte em sua totalidade, essas propriedades formais também passariam por uma "triagem", sendo "selecionadas, apuradas e sistematizadas" (SCHWARTZMANN, 2009) para o uso. Dessa forma, o tipo de suporte convocado e, especialmente, o uso que a enunciação/inscrição faz dessas tendências formais, revelam um modo de intencionalidade, que emerge de uma maneira específica e duradoura de se apropriar do suporte.

Esse gesto pode ser atribuído à instância enunciativa do texto. Isso significa que a passagem do nível dos objetos ao do texto-enunciado não consiste meramente na adequação da metalinguagem descritiva a uma dada semiótica-objeto. Mais do que isso, ela consiste em uma ferramenta metodológica importante que permite vislumbrar os primeiros mecanismos de triagem realizados pela instância enunciativa no âmbito do suporte e, com isso, uma primeira faceta de sua identidade.

\section{Manipulação e identidade no texto-enunciado do canal}

É especialmente difícil reconhecer qual é o enunciador do canal sem que se recorra a um repertório extratextual. Isto é, apenas um sujeito que conhece Companhia das Letras ou o YouTube poderá (re)construir essa informação (o lugar de inscrição de Companhia das Letras, no YT, é sempre destinado ao proprietário do canal). Já o enunciatário nos parece estar mais evidente. Figuras como "livro", "poema", "autora" e temas como "adquira já o seu [livro]" indicam que se trata do leitor de literatura que poderia vir a comprar obras:

Pela primeira vez, toda a lavra poética da autora de "Bufólicas" está reunida em um só livro, que inclui, além de mais de 20 títulos, uma seção de inéditos e fortuna crítica. O material contém posfácio de Victor Heringer, carta de Caio Fernando Abreu para Hilda, dois trechos de Lygia Fagundes Telles sobre a amiga e uma entrevista cedida a Vilma Áreas, publicada no "Jornal do Brasil" em 1989. A poesia de Hilda - que ganha forma em cantigas, baladas, sonetos e poemas de verso livre - explora a morte, a solidão, o amor erótico, a loucura e o misticismo. Ao fundir o sagrado e o profano, a poeta se firmou como uma das vozes mais transgressoras da literatura brasileira do século XX. "Da poesia" chega às livrarias no dia 24 de abril. Garanta o seu: Amazon: http://amzn.to/2n1u0wA Cultura: http:// bit.ly/2nfrl4v Saraiva: http://bit.ly/2n LcEnD Direção e edição: Maria Lutterbach Câmera: Haroldo Saboia Trilha: Collecting samples (Blue Dot Sessions) (CIA. DAS LETRAS, 2017).

Como o booktrailer é um gênero de divulgação inserido em uma prática de venda, podemos assumir de antemão que o objetivo do destinador é levar o destinatário à compra (enunciador e enunciatário, em outro nível). O que nos parece produtivo para este caso é entender como o destinatário é manipulado a cumprir esse percurso. 
Vejamos que o destinador adota formas distintas de manipulação (BARRos, 2003). A manipulação por sedução, que ocorre quando o destinador pressupõe uma imagem positiva do /saber/ do destinatário, o leitor de textos literários interessado por obras de vanguarda, conhecedor do jargão e da crítica, como mostra a citação anterior. Há também uma segunda forma de manipulação, a tentação, que ocorre ao passo que se destaca os aspectos positivos do objeto de venda, Da poesia (HILST, 2017): uma obra "transgressora" e "extensa" ("toda a lavra poética", "mais de vinte títulos"), diversa ("cantigas, sonetos, baladas"), oferecida ao destinatário um objeto (de conhecimento) supostamente capaz de lhe doar as competências necessárias para o papel de leitor competente.

Esse percurso de exaltação da obra, que permite delinear as estratégias de manipulação e a relação destinador/destinatário, constrói na dimensão dos atores o papel temático da escritora, porque associa todas essas qualidades da obra ao sujeito que a escreveu. No texto em análise, esse sujeito não está construído como uma escritora qualquer. Nele, a identidade "Hilda Hilst" é a de uma escritora voraz (só os poemas inéditos somam mais de 10 títulos), versátil (que escreveu "baladas", "cantigas", "sonetos", "versos livres"), reconhecida pela crítica ("Wilma Arêas", "Berta Waldman") e pelo cânone ("Lygia Fagundes Telles", "Caio Fernando Abreu") (CIA. DAS LETRAS, 2017). Quanto à obra, ela é destacada como a de uma literatura que "explora [temas como] a morte, a solidão, o amor erótico, a loucura e o misticismo" (CIA. DAS LETRAS, 2017).

Analisando o "Posfácio" (HILST, 2017) e considerando que ele desempenha no interior do livro a mesma função que a descrição desempenha no canal (apresentação, comentário etc.), podemos chegar a algumas conclusões. Como se vê a seguir, Companhia das Letras opta por manter no texto de divulgação, publicado em seu canal no YouTube, três temas que estão na gênese da "personalidade polêmica" de "Hilda" segundo o "Posfácio": o misticismo, a loucura e o erotismo:

[Hilda Hilst] [...] queria ser lida, lida mesmo, por leitores atentos. Suas entrevistas revelam como a própria autora se dedicou a construir sua imagem pública e a reivindicar espaço no meio literário. Essa autoconstrução [...] desaguou na imagem que hoje se tem de Hilda Hilst. Hilda, a reclusa da Casa do Sol [...]. Hilda, que apareceu no Fantástico nos anos de 1970 dizendo que grava vozes de mortos. Hilda, provocadora, desbocada, obscena, meio louca, eremita, arredia, indomesticável. (HILST, 2017, p. 553, grifos do autor).

As passagens em que os temas da loucura e do misticismo se encontram, funcionam especialmente como conectores de isotopia (GREIMAS; COURTÉS, 2016) e organizam grades de leitura dominantes. Ao construir, no texto do canal e no "Posfácio" da obra que busca vender, passagens que caracterizam a "vida" do sujeito "Hilda Hilst" a partir de temas análogos aos da poesia de Hilst, Companhia das Letras conduz o seu destinatário (comprador em potencial do livro) a criar uma ponte entre o universo discursivo literário, 
relativo ao sujeito autoral, e o universo discursivo da biografia, relativo ao sujeito histórico textualizado nas entrevistas que Hilst deixou. Dessa forma, o enunciatário que se constrói é o leitor que possivelmente se interessa pela vida ("polêmica", "imoral" etc.) dos escritores que lê.

Nesse aspecto, podemos dizer que a prática de pré-venda de Da poesia (HILST, 2017) é paradoxal se confrontada à estratégia anunciada na obra que o booktrailer busca vender. Segundo o que se anuncia ainda em "Posfácio", "o descompasso entre ser vista e ser lida foi uma constante no trabalho de Hilst" (HILST, 2017, p. 532). Se a estratégia adotada por essa edição fosse, de fato, a de reparar esse desequilíbrio ${ }^{9}$, o booktrailer deveria conter procedimentos de afastamento com relação aos temas e figuras que constroem essa identidade polêmica. Isto é, ele deveria fortalecer uma leitura da obra que se distanciasse das figuras e temas "imorais", frequentemente atribuídos à "Hilda". Isso deveria ocorrer porque o "discurso polêmico" sobre "Hilda" teria sido, justamente, um dos fatores responsáveis pela pouca visibilidade da obra de Hilst, segundo a crítica (cf. artigos da crítica no paratexto de Da poesia). Assim, as isotopias autoral e biográfica se conectam deste modo: o texto da descrição do vídeo indica que Hilst foi uma das "vozes mais transgressoras da literatura brasileira do século XX" (CIA. DAS LETRAS, 2017), o que nos leva a compreender, por suposição, que "Hilda" foi uma das mulheres mais transgressoras de seu tempo (cf. "Posfácio" de Da poesia).

\section{À guisa de conclusão: a prática de pré-venda}

Como buscamos demonstrar, é o ponto de vista das práticas semióticas o que nos permite tratar da complexidade e da dimensão contraditória dos dois discursos que se produzem sobre a obra de Hilst: no nível do parecer, a ênfase sobre a obra, e finalmente, no nível do ser, a manutenção de um discurso místico ou mítico em que vida e obra se confundem. Para isso, não basta identificar as formas de manipulação ou determinar as intertextualidades que ligam o booktrailer à obra, é preciso inseri-las em uma cena global, que comporta outros atos (apresentar, comentar etc.).

Atribuindo a organização desses atos a uma mesma instância produtora de sentido, podemos reconhecer um único projeto enunciativo (um projeto editorial) que se multiplica em práticas distintas (de pré-venda, de comentário, de uso de plataformas digitais), mantendo, no entanto, o seu objetivo final: construir uma imagem de Hilda Hilst para o leitor habitual da editora. Nesse sentido, vemos que a plataforma do YouTube possui, no interior da prática de pré-venda, uma função evidentemente modal, na medida em que o seu papel é o de levar o destinatário a firmar o contrato: a compra (e, por fim, a leitura).

9 Segundo o "Posfácio", como já pudemos indicar, a publicação de "Da poesia se inscreve no rol de iniciativas que buscam acertar esse compasso" (HILST, 2017, p. 532). 
A morfologia do suporte formal, os protocolos de interação e de uso fundam uma estratégia de venda de lógica permissiva, que permite realizar percursos distintos de leitura e de interação com o canal. Isso ocorre porque as competências atribuídas ao enunciatário, tanto no nível do objeto-suporte quanto no do texto-enunciado, jogam com as modalidades do /querer/ e do /poder/, mas nunca com a modalidade do / dever/. Se assumirmos, então, que tanto o canal no YT quanto o sujeito que o assiste desempenham um papel na cena prática de pré-venda analisada, mais que imputar uma junção, no sentido de promover no sujeito o desejo de apropriação de um objeto-valor e a consolidação desse desejo, essa prática fundaria uma união entre destinatário e o objeto destinado: o canal e a obra de Hilst.

Vejamos que ao deixar transparecer no plano da cognição, pela formulação discursiva dos temas e valores, o estado do sujeito-autor (conjunção com a imoralidade, com a polêmica e, de certa forma, com a permissividade) e projetar esses mesmos valores em um plano estético mais global que o da obra (no nível da significação fundada pela interação com o canal), o destinador leva seu destinatário a experienciar o mundo como Hilst o experimentava: permissivamente. Tudo se passa como se, "por uma espécie de performatividade da copresença sensível", isto é, "uma relação de união fundada" entre três sensibilidades (autoral, editorial e do leitor), a percepção das "manifestações somáticas" dos "estados vividos" por um sujeito (LANDOWSKI, 2014, p. 18) fosse capaz de fazer com que o destinatário seja, por união, contagiado por eles.

O ponto de vista das práticas semióticas revela então diferentes instâncias subjetivas, construídas no interior de instâncias enunciativas autônomas (possuem limites, papéis e funções descritíveis). Isto é, o ponto de vista do texto permite revelar a autonomia dessas instâncias, o ponto de vista das práticas as dependências e relações que estabelecem entre si, necessariamente para a boa forma da cena prática. Desse modo, no âmbito da prática de pré-venda, temos um destinatário matizado por diferentes sobremodalizações, o que nos leva a reconhecer, nessa prática, diferentes papéis actanciais: "usuário do YouTube", "seguidor do canal", "leitor de obras literárias", "comentador" etc.

É no interior desses desdobramentos que o destinatário pode reconhecer, na obra que Ihe é destinada como valor, temas muito próximos àqueles que teriam levado a obra de Hilda Hilst à exclusão do cenário nacional. Dessa maneira, a prática de pré-venda da Companhia das Letras buscaria resolver o problema da circulação da obra de Hilst por meio de um contrato cujo objetivo seria fidelizar um público que, a princípio, não se interessaria pela obra de Hilst, construindo para isso uma grade de leitura (via biografia) capaz de facilitar, em certa medida, a sua popularização.

Nesse sentido, como dizíamos, assumindo no interior da prática de edição um papel modal, a prática de pré-venda adota uma estratégia que concilia valores literários e comerciais. Isso ocorre na medida em que uma demanda literária (dar à obra de Hilst a 
mesma popularidade alcançada por sua "personalidade polêmica") se confunde com uma demanda de mercado (vender), de modo que "obra literária" e "lucro" (BOURDIEU, 2018, p. 222) são assumidos como objetos-valor de dois percursos distintos. Estes últimos, embora possuam diferentes desdobramentos, reencontram-se em um sincretismo de destinatários (em outro nível, editor e livreiro), que ocorre no interior de duas práticas correlacionadas: uma prática de pré-venda e uma prática de edição, esta última produzindo o livro que se quer "pré-vender".

Do ponto de vista da Semiótica, vemos que a proposta dos níveis é uma ferramenta importante para dar conta da existência cultural dos objetos de sentido, pois permite depreender os mecanismos socioletais que estão nas bases de sua valorização. Do ponto de vista dos estudos sobre o texto de literatura, a proposta fontanilliana permite lançar um novo olhar sobre a obra literária. A questão do valor (e por extensão do cânone) pode ser deslocada para o conjunto de fatores que atuam pelas bordas do texto (edição, divulgação etc.) e que parecem determinar, tanto quanto as escolhas autorais, as modalidades de circulação, o valor e o estatuto, da obra literária.

\section{Referências}

AREAAS, V.; WALDMAN, B. Hilda Hilst - o excesso em dois registros. Jornal do Brasil, Rio de Janeiro, 3 de out. 1989.

BARROS, D. L. P. de. Teoria semiótica do texto. São Paulo: Ática, 2003.

BARROS, D. L. P. de. Teoria do discurso: fundamentos semióticos. São Paulo: Humanitas, 2001.

BOURDIEU, P. Uma revolução conservadora na edição. Política e sociedade. Revista de Sociologia Política, v. 17, n. 39, p. 198-248, 2018. Disponível em: https://periodicos.ufscr/ index.php/politica/article/view/21757984.2017v17n39p198/37845. Acesso em: 10 jul. 2018 .

BURGESS, J.; GREEN, J. Youtube e a revolução digital: como o maior fenômeno da cultura participativa está transformando a mídia e a sociedade. São Paulo: Aleph, 2009.

CASTRO, G. H. R. de. A edição como prática semiótica: estudo da identidade editorial "Hilda Hilst" em Da poesia. 2021. Dissertação (Mestrado em Linguística e Língua Portuguesa) - Faculdade de Filosofia, Ciências e Letras, Universidade Estadual Paulista "Júlio de Mesquita Filho", Araraquara, 2021. Disponível em: https://repositorio.unesp.br/ handle/11449/204453. Acesso em: 29 nov. 2021. 
COMPANHIA DAS LETRAS. Booktrailer: da poesia [on-line]. São Paulo: Companhia das letras, 2017. Disponível em: https://www.youtube.com/watch?v=3P6f2 HeXEtM\&t=18s. Acesso em: 10 set. 2020.

DINIZ, C. Fico besta quando me entendem: entrevistas com Hilda Hilst. São Paulo: Biblioteca Azul, 2013.

FIORIN, J. L. As astúcias da enunciação. 2. ed. São Paulo: Ática, 2016.

FIORIN, J. L. Da necessidade de distinção entre texto e discurso. In: BRAIT, B.; SOUZA-ESILVA, M. C. (org.). Texto ou discurso? São Paulo: Contexto, 2012. p. 146-165.

FIORIN, J. L. Interdiscursividade e intertextualidade. In: BRAIT, B. (org.). Bakhtin: outros conceitos-chave. São Paulo: Contexto, 2010a. p. 161-193.

FONTANILLE, J. Semiótica do discurso. 2. ed. Tradução Jean Cristtus Portela. São Paulo: Contexto, 2015.

FONTANILLE, J. Práticas semióticas: imanência e pertinência, eficiência e otimização. In: DINIZ, M. L. V. P.; PORTELA, J. C. (org.). Semiótica e mídia: textos, práticas, estratégias. São Paulo: UNESP/FAAC, 2008a. p. 15-74.

FONTANILLE, J. Pratiques Sémiotiques. Paris: PUF, 2008b.

FONTANILLE, J. Du support matériel au support formel. In: KLOCK-FONTANILLE, I.; ARABYAN, M. (org.). L'écriture entre support et surface. Paris: L'Harmattan, 2005. p. 183200.

GENETTE, G. Paratextos editoriais. Cotia: Ateliê Editorial, 2009.

GUALBERTO, A. C. Hilda Hilst e Beatriz Francisca de Assis Brandão: um diálogo sobre a autoria feminina. Revista Ártemis, v. 19, 16 out. 2015. Disponível em: https://periodicos. ufpb.br/index.php/artemis/article/view/26196/14090. Acesso em: 10 set. 2020.

GREIMAS, A. J.; COURTÉS, J. Dicionário de Semiótica. 2 ed. 3 reimp. São Paulo: Contexto, 2016.

HERINGER, V. Posfácio. In: HILST, H. Da poesia. São Paulo: Contexto, 2017. 
HOUAISS. Dicionário Eletrônico. Versão 3. 0. 1. 48. Editora Objetiva, 2009.

HILST, H. Da poesia. São Paulo: Companhia das Letras, 2017.

LANDOWSKI, E. De la stratégie, entre programmation et ajustement. Nouveaux Actes Sémiotiques. n. 89-91. Limoges: Pulim, 2003.

PORTELA, J. C. Conversations avec Jacques Fontanille. Revista Alfa, UNESP, n. 50, v. 1, p. 159-186, 2006. Disponível em: http://www.alfa.ibilce.unesp.br/download/ v5 0/1 2 PORTELA.pdf. Acesso em: 30 ago. 2019.

SCHCOLNIK, F. Hilda Hilst: escritora maldita? Estação Literária, Londrina, v. 12, p. 452468, jan. 2014. Disponível em: http://www.uel.br/pos/letras/EL/vagao/EL12-Art29.pdf. Acesso em: 10 set. 2020.

SCHWARTZMANN, M. N. A noção de texto e os níveis de pertinência da análise semiótica. Estudos Semióticos, v. 14, n. 1, p. 1-6, 2018. Disponível em: https://www. revistas.usp.br/esse/article/view/144288. Acesso em: 10 set. 2020.

SCHWARTZMANN, M. N. Elogio e depreciação no comentário on-line. In: ABRIATA, V. L. et al. Leitura: a circulação dos discursos na contemporaneidade. Franca: EDUNIFRAN, 2013. p. 55-85.

SCHWARTZMANN, M. N. Cartas marcadas: prática epistolar e formas de vida na correspondência de Mário de Sá-Carneiro. 2009. Tese (Doutorado em Linguística e Língua Portuguesa) - Faculdade de Filosofia, Ciências e Letras, Universidade Estadual Paulista "Júlio de Mesquita Filho", Araraquara, 2009. Disponível em: https://repositorio. unesp.br/handle/11449/103560. Acesso em: 10 set. 2020.

SILVA, C. A. da. A prática da psicografia. Corpo e transmissão em relatos de experiência mediúnica. 2016. Tese. (Doutorado em Linguística e Língua Portuguesa) - Faculdade de Ciências e Letras, Universidade Estadual Paulista "Júlio de Mesquita Filho", Araraquara. Disponível em: https://repositorio.unesp.br/handle/511/silva_ca_arafcl.pdf ?sey. Acesso em: 10 out. 2018.

ZILBERBERG, C.; FONTANILLE, J. Tensão e significação. São Paulo: Discurso Editorial/ Humanitas, 2001. 